Research paper

\title{
Influence of nutritional and operational parameters on the production of butanol or 1,3-propanediol from glycerol by a mutant Clostridium pasteurianum
}

\author{
R. Gallardo ${ }^{1}$, M. Alves, L.R. Rodrigues* \\ CEB - Centre of Biological Engineering, University of Minho, 4710-057 Braga, Portugal
}

\section{A R T I C L E I N F O}

\section{Article history:}

Available online 7 May 2016

\begin{abstract}
A B S T R A C T
Butanol and 1,3-propanediol (1,3-PDO) are simultaneously produced by Clostridium pasteurianum from glycerol. In this study, random chemical mutagenesis of $C$. pasteurianum DSM 525 was conducted to improve its tolerance to butanol. Selected nutritional and operational parameters were evaluated to identify strategies that favour the production of each metabolite. From those experiments, it was possible to isolate cells able to produce $22 \%$ more butanol than the parent strain in serum bottles. The supplementation of the culture medium with $2 \mathrm{mgl}^{-1}$ of iron increased the production of butanol by $163 \%$, and the optimum inoculum age was found to be 12 hours. Overall, the experiments conducted in bioreactor led to lower butanol titers than in serum bottles, which is attributed to the higher pressure present in the bottles. At $\mathrm{pH} 6.0, \mathrm{~N}_{2}$ sparging notoriously favoured the production of biomass and 1,3$\mathrm{PDO}$, while a lower $\mathrm{pH}$ (5.0) led to a higher butanol yield, although growth was negatively affected. The results herein gathered allowed the identification of specific conditions that favour the production of either butanol or 1,3-PDO. Furthermore, it was found that $\mathrm{N}_{2}$ sparging is a suitable strategy to maximize the titer, yield and productivity of 1,3-PDO using C. pasteurianum.
\end{abstract}

(c) 2016 Elsevier B.V. All rights reserved.

\section{Introduction}

Over the last years, several efforts have been conducted towards the maximization of butanol production by Clostridium spp., including strategies to develop butanol-tolerant strains, but also to optimize the production conditions [1-3].

Several Clostridium spp. produce butanol from sugars, yet $C$. pasteurianum is the only microorganism known to produce it from glycerol - a by-product of biodiesel industry - as the sole carbon source [4]. In the fermentation of glycerol by this microorganism, 1,3-PDO is produced as an additional electron sink required to maintain the redox balance [5]. However, the ratio in which these metabolites are produced depends on several nutritional and operational parameters [2,3,5-7], and probably also on inhibitory effects that redirect both carbon and electron flow.

The toxic effect that solvents, in particular butanol, exert on Clostridium spp. limits its concentration in the fermentation broth resulting in low titers and productivities, as well as in incomplete substrate consumption. Butanol-tolerant strains have been mainly achieved by serial enrichment using increasing butanol

\footnotetext{
* Corresponding author.

E-mail address: 1rmr@deb.uminho.pt (L.R. Rodrigues).

1 Present address: Escuela de Ingeniería Bioquímica, Pontificia Universidad Católica de Valparaíso. Valparaíso, Chile.
}

concentrations and random chemical mutagenesis [2,8-10]. The alternative directed mutagenesis of Clostridium spp. is still a difficult approach since solvent tolerance is a complex metabolic response involving a large number of genes [11-15], and often not enough genetic information about the target microorganisms is available. Furthermore, tools for directed mutagenesis specific for Clostridium spp. were not available until a few years ago [16-18]. Nevertheless, several promising results regarding the use of chemical random mutagenesis to develop butanol-tolerant Clostridium strains have been reported [2,10,19,20]. N-Ethyl-Nnitrosourea (ENU) is a potent monofunctional-ethylating agent that is mutagenic in several systems from viruses to mammalian cells [21]; though it has not been used in clostridia. A potential advantage of using ENU over Ethyl methanesulfonate (EMS) or $\mathrm{N}$ methyl- $N^{\prime}$-nitro- $N$-nitrosoguanidine (NTG) is that this mutagenic compound is able to produce a wider range of mutations and hence, $a$ higher number of different genotypes and/or mutant strains genotypically more distant from the parent strain. EMS and NTG primarily produce GC-AT transitions, while ENU has showed to produce a number of other mutations, including A-T transversions, and AT-GC transitions, among others [22-24]. Therefore, ENU was herein used as it could increase the chances of producing the desired phenotype.

Medium composition and operational parameters play an important role in the solvents production by Clostridium spp. For 


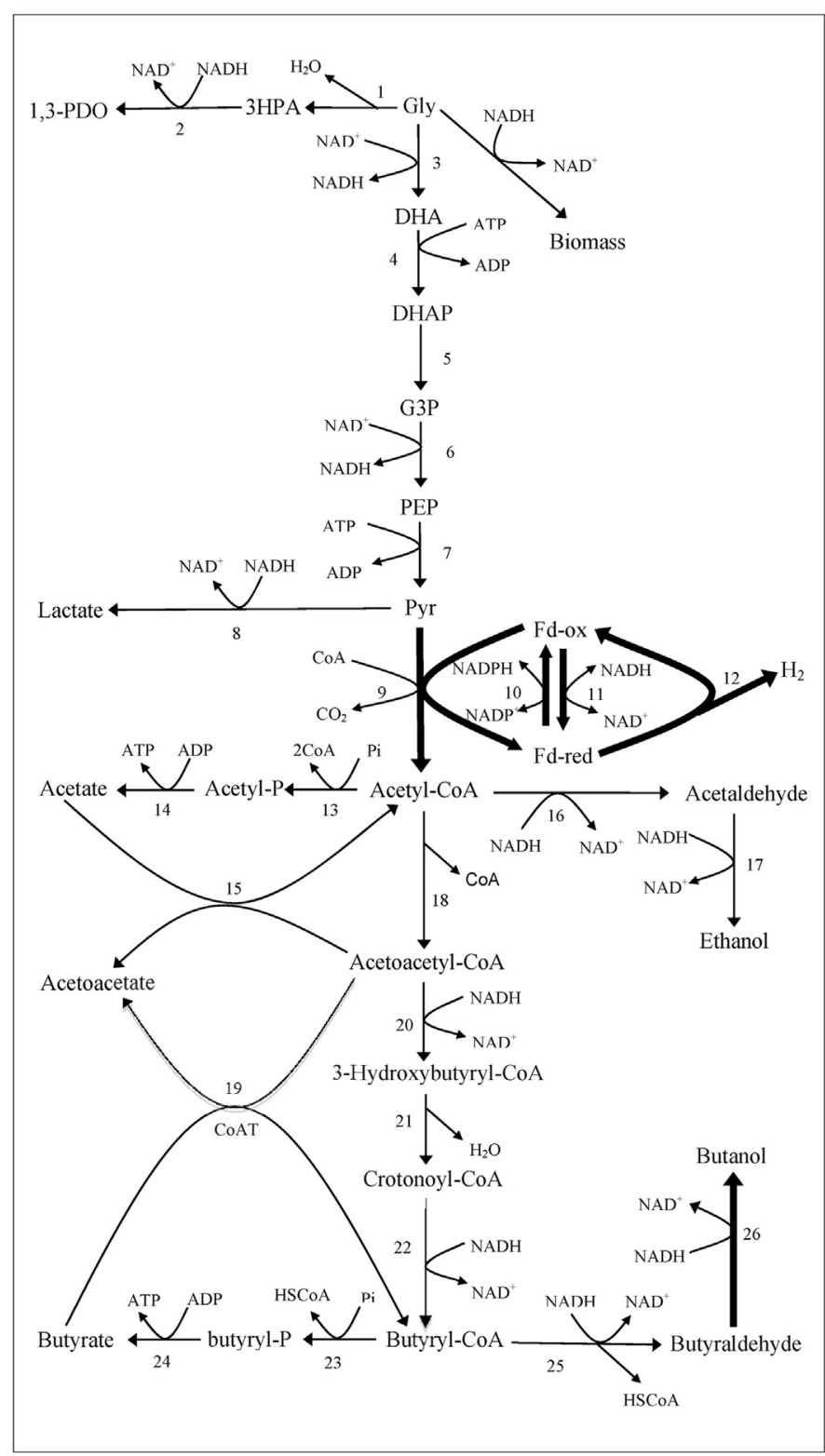

Figure 1. Metabolic pathways involved in the glycerol degradation by Clostridium pasteurianum. 1: glycerol dehydratase; 2: 1,3-propanediol oxidoreductase; 3: glycerol-3-phosphate dehydrogenase; 4: dihydroxyacetone kinase; 5: triosephosphate isomerase; 6: glyceraldehyde-3-phosphate dehydrogenase; 7: pyruvate kinase; 8: lactate dehydrogenase; 9: pyruvate-ferredoxin oxidoreductase; 10: NADPH-ferredoxin oxidoreductase; 11: NADH-ferredoxin oxidoreductase; 12: ferredoxin hydrogenase; 13: phosphate acetyltransferase; 14: acetate kinase; 15 : acetoacetyl-CoA: acetate: $\mathrm{CoA}$ transferase; 16: acetaldehyde dehydrogenase; 17: ethanol dehydrogenase; 18: thiolase; 19: acetoacetyl-CoA: butyrate:CoA transferase; 20: $\beta$-hydroxybutyryl-CoA dehydrogenase; 21: crotonase; 22: butyryl-CoA dehydrogenase; 23: phosphotransbutyrylase; 24: butyrate kinase; 25 : butaraldehyde dehydrogenase; 26: butanol dehydrogenase. Thick arrows correspond to reactions involving iron-containing enzymes/proteins.

Source: Adapted from Malaviya et al. [2].

instance, the iron concentration in the culture medium and the inoculum age, have been recognized as important variables. Iron is part of at least four important enzymes/proteins (Fig. 1), namely pyruvate-ferredoxin oxidoreductase [25], ferredoxin [26], hydrogenases I and II [27] and iron-containing alcohol dehydrogenase family proteins [28].

On the other hand, the inoculum age directly influences cell growth, productivity and reproducibility of the fermentations because, depending on their physiological state, the microorganisms react in a different way to $\mathrm{pH}$ fluctuations and stress conditions that are involved in their transfer to fresh culture medium [29]. Despite this, the effect of the inoculum age in the production of solvents by $C$. pasteurianum has been rather neglected, with few exceptions $[2,30]$.

Even though the use of serum bottles is a common practice for batch culturing of anaerobic microorganisms, scale-up of fermentation processes requires the use of lab scale bioreactors that allow the control of key parameters such as pressure, $\mathrm{pH}$ and agitation. Serum bottles are commonly over pressured and periodic release of gas is required during the fermentation. This situation leads to an increase of the $\mathrm{H}_{2}$ and $\mathrm{CO}_{2}$ partial pressure, which in turn could affect the outcome of the fermentation by inhibiting key enzymes. The $\mathrm{pH}$ of the fermentation has also been reported as an important variable in butanol production by Clostridium spp. However, the optimum $\mathrm{pH}$ range for solvent production varies significantly among species. Furthermore, the effect of $\mathrm{pH}$ in $C$. pasteurianum fermentation has been barely studied. The fermentation of glycerol by this microorganism at constant $\mathrm{pH}$ values has been reported by Biebl [5], but without conclusive results. Sparging of an inert gas and agitation are directly related with the mass transfer phenomenon in the fermentation. These variables can be controlled in a lab-scale bioreactor thus affecting the level of dissolved $\mathrm{H}_{2}$ and $\mathrm{CO}_{2}$ in the fermentation broth, which in turn will influence the solvent production [31,32].

In this work, random mutagenesis of $C$. pasteurianum DSM 525 in solid medium using ENU was conducted. Mutant cells were evaluated for their ability to produce butanol in liquid medium. Subsequently, the effects of iron concentration and inoculum age on the production of butanol and 1,3-PDO by the mutant strain were evaluated. Finally, experiments were conducted in a lab-scale bioreactor with $\mathrm{pH}$ control and $\mathrm{N}_{2}$ sparging.

\section{Materials and methods}

\section{Strain maintenance and reactivation}

Freeze dried cells of Clostridium pasteurianum DSM 525 were reactivated and maintained in serum bottles as described by Gallardo et al. [33]. Briefly, a semi-defined culture medium containing per liter: $40 \mathrm{~g}$ glucose; $1 \mathrm{~g}$ yeast extract; $0.5 \mathrm{~g} \mathrm{K \textrm {K } _ { 2 }} \mathrm{PO}_{4}$; $0.5 \mathrm{~g} \mathrm{~K}_{2} \mathrm{HPO}_{4} ; 0.2 \mathrm{~g} \mathrm{MgSO}_{4} \cdot 7 \mathrm{H}_{2} \mathrm{O} ; 0.02 \mathrm{~g} \mathrm{CaCl}_{2} \cdot 2 \mathrm{H}_{2} \mathrm{O} ; 3 \mathrm{~g} \mathrm{NH}_{4} \mathrm{Cl} ; 4 \mathrm{~g}$ $\mathrm{NaH}_{2} \mathrm{CO}_{3} ; 0.5 \mathrm{~g}$ cysteine- $\mathrm{HCl} ; 1 \mathrm{ml}$ acid micronutrients solution (1.8 $\mathrm{g} \mathrm{l}^{-1} \mathrm{HCl} ; 61.8 \mathrm{mgl}^{-1} \mathrm{H}_{3} \mathrm{BO}_{3} ; 61.3 \mathrm{mgl}^{-1} \mathrm{MnCl}_{2} ; 943.5 \mathrm{mg} \mathrm{l}^{-1}$ $\left.\mathrm{FeCl}_{2} ; 64.5 \mathrm{mgl}^{-1} \mathrm{CoCl}_{2} ; 12.9 \mathrm{mg} \mathrm{l}^{-1} \mathrm{NiCl}_{2} ; 67.7 \mathrm{mgl}^{-1} \mathrm{ZnCl}_{2}\right)$ and $1 \mathrm{ml}$ alkaline micronutrients solution $\left(0.4 \mathrm{gl}^{-1} \mathrm{NaOH} ; 17.3 \mathrm{mg} \mathrm{l}^{-1}\right.$ $\mathrm{Na}_{2} \mathrm{SeO}_{3} ; 29.4 \mathrm{mg} \mathrm{l}^{-1} \mathrm{Na}_{2} \mathrm{WO}_{4} ; 20.5 \mathrm{mg} \mathrm{l}^{-1} \mathrm{Na}_{2} \mathrm{MoO}_{4}$ ) under a $\mathrm{N}_{2^{-}}$ $\mathrm{CO}_{2}$ gas mixture (80-20\%) atmosphere in the head space, was used. Stock cultures were kept at room temperature and were transferred to fresh medium periodically.

\section{Analytical methods}

Acids, glycerol and 1,3-PDO were measured as described by Gallardo et al. [33]. Briefly, high performance liquid chromatography (Aminex cation-exchange HPX-87H column) equipped with UV and RI detectors, was used. The column was isocratically eluted with $\mathrm{H}_{2} \mathrm{SO}_{4} 0.01 \mathrm{~N}$ using a flow rate of $0.7 \mathrm{ml} \mathrm{min}^{-1}$. The column temperature was set at $60^{\circ} \mathrm{C}$. Ethanol and butanol were measured by gas chromatography (TR-WAX capillary column) equipped with a flame ionization detector. A temperature $\operatorname{ramp}\left(0.5^{\circ} \mathrm{C} \mathrm{min}^{-1}\right)$ was used for the column and the temperatures of the injector and detector were kept at $200^{\circ} \mathrm{C}$ and $250^{\circ} \mathrm{C}$, respectively.

Cell growth was monitored during fermentation by measuring the optical density (OD) at $600 \mathrm{~nm}$. The biomass from $20 \mathrm{ml}$ cell suspension, in triplicate, was dried in an $80^{\circ} \mathrm{C}$ oven for 48 hours 
and the dry cell weight (DCW) was determined. The optical densities were then converted to DCW $\mathrm{l}^{-1}$ using the following correlation: $\mathrm{OD}_{600 \mathrm{~nm}}=3.28 \times \mathrm{DCW}\left(\right.$ in $\left.\mathrm{gl}^{-1}\right)+0.048, r^{2}=0.999$.

\section{Random mutagenesis}

Modified Reinforced Clostridial Medium (mRCM) containing $20 \mathrm{gl}^{-1}$ glucose was used in the mutagenesis experiments. The medium was dispensed in four individual $250 \mathrm{ml}$ Erlenmeyer flasks and agar was added to each flask up to a final concentration of $17 \mathrm{~g} \mathrm{l}^{-1}$ before sterilization. The culture media was let to cool down and butanol was aseptically added before it became solid. Butanol concentrations used in these assays were $0,12,15$ and $20 \mathrm{gl}^{-1}$. Four disposable Petri dishes were prepared for each butanol concentration. The plates were placed inside a vinyl anaerobic chamber (Coy Laboratory Products) at least 3 hours before the mutagenesis experiment was conducted to ensure the absence of oxygen.

Random mutagenesis in C. pasteurianum DSM 525 was conducted as described by Hermann and collaborators $[8,9]$ with minor modifications. A crystal of ENU was placed at the centre of each plate containing mRCM supplemented with butanol. Two plates without the mutagenic agent were used as control for each butanol concentration tested. After $15 \mathrm{~min}, 200 \mu \mathrm{l}$ of an exponential-phase culture of $C$. pasteurianum DSM 525 grown in $\mathrm{mRCM}$ were spread on each plate. The plates were then incubated at $37^{\circ} \mathrm{C}$ inside an anaerobic box until growth was observed (typically between 48 and 72 hours).

Colonies growing at butanol concentrations that did not allow the growth of the parent strain (controls) were selected and purified by transferring them to Petri dishes containing the same culture medium composition and butanol concentration, but without the mutagenic agent. To test their ability to produce butanol and compare them with the parent strain, those colonies were transferred to $20 \mathrm{ml}$ liquid mRCM (serum bottles), and after 24 hours, a $60 \mathrm{ml}$ of the semi-defined culture medium described in the section 'Strain maintenance and reactivation', but using $45 \mathrm{~g} \mathrm{l}^{-1}$ of glycerol instead of glucose was inoculated with $10 \%(\mathrm{v} / \mathrm{v})$ of this culture. Besides, the $\mathrm{CO}_{2}-\mathrm{NaH}_{2} \mathrm{CO}_{3}$ buffer system was replaced by $\mathrm{CaCO}_{3}$ under a $\mathrm{N}_{2}$ atmosphere.

In order to confirm the butanol tolerance of the mutant strains, cells were challenged with different concentrations of butanol $(0$, 5,10 , and $\left.15 \mathrm{gl}^{-1}\right)$. Mutant strains at exponential growth phase were used to inoculate $(10 \%, v / v)$ the semi-defined culture medium described above, containing $80 \mathrm{gl}^{-1}$ glycerol and the desired butanol concentration.

\section{Effect of iron concentration and inoculum age}

The isolated strain was cultured in $160 \mathrm{ml}$ serum bottles containing $60 \mathrm{ml}$ of the semi-defined culture medium described in 'Strain maintenance and reactivation', but using $85 \mathrm{gl}^{-1}$ glycerol instead of glucose. To evaluate the effect of iron concentration, a modified acid micronutrients solution (Strain maintenance and reactivation) was prepared without Fe. Afterwards, the culture medium was supplemented with different concentrations of $\mathrm{FeSO}_{4} \cdot 7 \mathrm{H}_{2} \mathrm{O}$, which resulted in $0,0.6,2,10$, and $20 \mathrm{mgl}^{-1}$ of $\mathrm{Fe}$. Six milliliters of the culture medium were inoculated at $10 \%(\mathrm{v} / \mathrm{v})$.

To study the effect of the inoculum age, cells were transferred to fresh medium at $12,16,20,24$, and 36 hours after inoculation and samples were taken until no further change in the concentration of the measured metabolites was observed.

\section{Experiments in lab-scale bioreactor}

The butanol-tolerant mutant of $C$. pasteurianum herein isolated was further tested in a $1.5 \mathrm{~L}$ stirred bioreactor (Autoclavable benchtop fermentor Type R'ALF, Bioengineering AG, Wald, Switzerland), equipped with two Rushton flat blade turbines, condenser, $\mathrm{pH}$ and temperature control. The working volume used was $1.2 \mathrm{~L}$. A semi-defined culture medium containing per liter of distilled water: $90 \mathrm{~g}$ glycerol, $1 \mathrm{~g}$ yeast extract, $0.5 \mathrm{~g}$ $\mathrm{KH}_{2} \mathrm{PO}_{4}, 0.5 \mathrm{~g} \mathrm{~K}_{2} \mathrm{HPO}_{4}, 0.2 \mathrm{~g} \mathrm{MgSO} \cdot 7 \mathrm{H}_{2} \mathrm{O}, 0.02 \mathrm{~g} \mathrm{CaCl}_{2} \cdot 2 \mathrm{H}_{2} \mathrm{O}$, $50 \mathrm{mg} \mathrm{FeSO}_{4} \cdot 7 \mathrm{H}_{2} \mathrm{O}, 5 \mathrm{~g} \mathrm{NH} \mathrm{Nl}_{4}, 0.5 \mathrm{~g}$ cysteine- $\mathrm{HCl}, 1 \mathrm{ml}$ acid micronutrients solution and $1 \mathrm{ml}$ alkaline micronutrients solution (Strain maintenance and reactivation) was used. Since a higher glycerol consumption was expected in these experiments as comparison to those conducted in serum bottles, $\mathrm{FeSO}_{4} \cdot 7 \mathrm{H}_{2} \mathrm{O}$ was added at a final concentration of $50 \mathrm{mg} \mathrm{l}^{-1}$. The reactor containing $1 \mathrm{~L}$ of concentrated culture medium (except glycerol and $\mathrm{FeSO}_{4} \cdot 7 \mathrm{H}_{2} \mathrm{O}$ ) was autoclaved for $30 \mathrm{~min}$. Sterile concentrated glycerol and $\mathrm{FeSO}_{4} \cdot 7 \mathrm{H}_{2} \mathrm{O}$ solutions accounting for $80 \mathrm{ml}$ were aseptically added to the bioreactor. Then, the bioreactor was flushed with sterile oxygen-free nitrogen gas until room temperature was reached. The nitrogen gas was sterilized through a filter, introduced at the bottom of the bioreactor and dispersed into the liquid through a circular sparger. The bioreactor was inoculated with an early exponential growth phase ( 12 hours) culture $(10 \%, v / v)$. The inoculum was prepared from a sporulated stock culture. The agitation was set at $150 \mathrm{rpm}$ and the temperature was kept at $37^{\circ} \mathrm{C}$ by means of an external jacket for water circulation. The initial $\mathrm{pH}$ was set at 6.8 and it was controlled during the fermentation by addition of $\mathrm{NaOH} 2 \mathrm{M}$. The $\mathrm{N}_{2}$ flow fed to the reactor was controlled by a mass flow controller (Aalborg).

Three different experimental conditions were explored to assess the impact of $\mathrm{pH}$ and $\mathrm{N}_{2}$ sparging on the fermentation outcome:

a. Constant pH 6.0 and $0.5 \mathrm{vvm} \mathrm{N}_{2}$ during the whole fermentation. b. Constant $\mathrm{pH} 6.0$ and $0.1 \mathrm{vvm} \mathrm{N}_{2}$ only during the lag phase. c. Constant pH 5.0 and $0.1 \mathrm{vvm} \mathrm{N}_{2}$ only during the lag phase.

\section{Results}

\section{Random mutagenesis experiments}

After 72 hours of incubation, two colonies were obtained in a Petri dish containing $12 \mathrm{~g} \mathrm{l}^{-1}$ of butanol and ENU. No growth was observed in the controls using this butanol concentration or in any Petri dish with a higher butanol concentration. These colonies were purified and a total of nine colonies were transferred to liquid medium for testing their ability to produce solvents, as well as to compare them with the parent strain. The results obtained are presented in Table 1.

The isolated mutant strain M2 produced the highest amount of butanol, corresponding to a final titer of $8.72 \pm 0.07 \mathrm{gl}^{-1}$, which represents a $22 \%$ increase in the production of butanol and a $17 \%$ increase in its yield on glycerol in comparison with the parent strain MC under the same culture conditions. Regarding the glycerol consumption, no appreciable difference was found between the strains $\mathrm{M} 2$ and $\mathrm{MC}\left(36.13 \pm 2.38 \mathrm{gl}^{-1}\right.$ versus $34.60 \pm 2.53 \mathrm{~g} \mathrm{l}^{-1}$ in the control). Furthermore, the 1,3-PDO yield was similar for both strains $\left(0.2 \mathrm{~g} \mathrm{~g}^{-1}\right)$, while a lower concentration of acids, particularly butyrate was observed at the end of the fermentation using the strain M2.

Once challenged with different butanol concentrations, the strain M2 was able to grow in a culture medium containing up to $10 \mathrm{gl}^{-1}$ of butanol (twice the concentration at which the parent strain was able to grow), reaching a final butanol concentration of $12.06 \pm 0.15 \mathrm{~g} \mathrm{l}^{-1}$, thus confirming the results obtained in solid medium. However, it is important to notice that the final 
Table 1

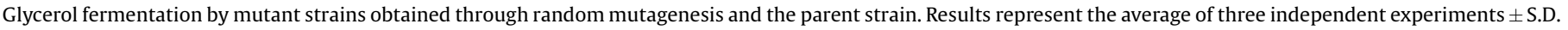

\begin{tabular}{|c|c|c|c|c|c|c|c|c|c|c|}
\hline $\begin{array}{l}\text { Substrate/product } \\
\left(\mathrm{gl}^{-1}\right)\end{array}$ & M1 & M2 & M3 & M4 & M5 & M6 & M7 & M8 & M9 & MC \\
\hline Glycerol initial & $45.26 \pm 4.03$ & $46.10 \pm 4.07$ & $45.80 \pm 3.69$ & $45.56 \pm 5.87$ & $45.91 \pm 5.34$ & $43.20 \pm 3.95$ & $46.84 \pm 1.98$ & $45.09 \pm 2.68$ & $46.52 \pm 0.93$ & $46.38 \pm 3.66$ \\
\hline Glycerol final & $10.67 \pm 1.92$ & $9.97 \pm 1.69$ & $10.68 \pm 1.68$ & $9.08 \pm 4.98$ & $10.02 \pm 3.74$ & $14.62 \pm 2.92$ & $10.30 \pm 2.66$ & $10.40 \pm 1.65$ & $10.44 \pm 1.50$ & $11.78 \pm 1.13$ \\
\hline $\begin{array}{l}\text { Glycerol } \\
\text { consumption }\end{array}$ & $34.59 \pm 2.12$ & $36.13 \pm 2.38$ & $35.12 \pm 2.01$ & $36.48 \pm 0.89$ & $35.88 \pm 1.60$ & $28.58 \pm 1.03$ & $36.54 \pm 0.68$ & $34.68 \pm 1.03$ & $36.09 \pm 0.57$ & $34.60 \pm 2.53$ \\
\hline Butanol initial & $0.39 \pm 0.01$ & $0.40 \pm 0.00$ & $0.39 \pm 0.01$ & $0.41 \pm 0.05$ & $0.38 \pm 0.01$ & $0.32 \pm 0.00$ & $0.40 \pm 0.01$ & $0.39 \pm 0.01$ & $0.38 \pm 0.03$ & $0.31 \pm 0.02$ \\
\hline Butanol final & $8.07 \pm 0.38$ & $8.72 \pm 0.07$ & $8.05 \pm 0.23$ & $8.53 \pm 0.03$ & $8.37 \pm 0.15$ & $7.13 \pm 0.07$ & $8.08 \pm 0.19$ & $7.98 \pm 0.16$ & $7.93 \pm 0.40$ & $7.13 \pm 0.13$ \\
\hline Butanol yield & $0.22 \pm 0.00$ & $0.23 \pm 0.01$ & $0.22 \pm 0.01$ & $0.22 \pm 0.01$ & $0.22 \pm 0.01$ & $0.24 \pm 0.01$ & $0.21 \pm 0.01$ & $0.22 \pm 0.00$ & $0.21 \pm 0.01$ & $0.20 \pm 0.01$ \\
\hline 1,3-PDO initial & 0 & 0 & 0 & $0.14 \pm 0.18$ & $0.03 \pm 0.04$ & 0 & 0 & 0 & 0 & 0 \\
\hline 1,3-PDo final & $7.52 \pm 0.16$ & $7.25 \pm 0.32$ & $7.38 \pm 0.62$ & $7.88 \pm 0.33$ & $8.25 \pm 0.44$ & $4.91 \pm 0.72$ & $8.53 \pm 0,06$ & $7.47 \pm 0.81$ & $7.65 \pm 0.74$ & $6.79 \pm 0.23$ \\
\hline 1,3-PDO yield & $0.22 \pm 0.01$ & $0.20 \pm 0.00$ & $0.21 \pm 0.01$ & $0.21 \pm 0.01$ & $0.23 \pm 0.00$ & $0.17 \pm 0.02$ & $0.23 \pm 0.01$ & $0.22 \pm 0.03$ & $0.21 \pm 0.02$ & $0.20 \pm 0.01$ \\
\hline Acetate initial & 0 & 0 & 0 & 0 & 0 & 0 & 0 & 0 & 0 & 0 \\
\hline Acetate final & $0.72 \pm 0.02$ & $0.60 \pm 0.00$ & $0.73 \pm 0.08$ & $0.77 \pm 0.00$ & $0.85 \pm 0.04$ & $0.69 \pm 0.02$ & $0.87 \pm 0.03$ & $0.83 \pm 0.01$ & $0.80 \pm 0.04$ & $0.87 \pm 0.07$ \\
\hline Butyrate initial & 0 & 0 & 0 & 0 & 0 & 0 & 0 & 0 & 0 & 0 \\
\hline Butyrate final & $0.33 \pm 0.04$ & $0.14 \pm 0.01$ & $0.64 \pm 0.04$ & $0.16 \pm 0.23$ & $0.59 \pm 0.16$ & $1.29 \pm 0.45$ & $0.86 \pm 0.10$ & $0.77 \pm 0.13$ & $0.42 \pm 0.04$ & $0.90 \pm 0.00$ \\
\hline Lactate initial & $0.20 \pm 0.00$ & $0.20 \pm 0.00$ & $0.20 \pm 0.00$ & $0.20 \pm 0.00$ & $0.20 \pm 0.00$ & $0.20 \pm 0.00$ & $0.20 \pm 0.00$ & $0.20 \pm 0.00$ & $0.20 \pm 0.00$ & $0.20 \pm 0.00$ \\
\hline Lactate final & $1.48 \pm 0.04$ & $1.28 \pm 0.08$ & $1.22 \pm 0.09$ & $1.55 \pm 0.03$ & $1.61 \pm 0.06$ & $1.70 \pm 0.63$ & $1.78 \pm 0.01$ & $1.59 \pm 0.12$ & $1.30 \pm 0.24$ & $1.64 \pm 0.09$ \\
\hline
\end{tabular}

Nomenclature: M1-M9: cultures started from nine colonies isolated in solid medium containing $12 \mathrm{gl}^{-1}$ of butanol (mutants).

MC: Control - parent strain used in the mutagenesis experiment.

concentration of butanol achieved in the control culture (without externally added butanol) was $8.77 \pm 0.23 \mathrm{gl}^{-1}$.

\section{Iron and inoculum age}

The concentration of iron in the culture medium was found to influence both butanol production and glycerol consumption (Fig. 2). Iron limitation led to a lower glycerol consumption and solvent production. The culture medium supplementation with $2 \mathrm{mg} \mathrm{l}^{-1}$ of Fe yielded a $163 \%$ increase in the production of butanol. However, an increase in the Fe concentration over this value did not result in considerable differences. The production of 1,3-PDO was not affected by the Fe concentration.

The inoculum age also showed a significant impact on the fermentation of glycerol by C. pasteurianum M2 (Fig. 3). Twelve hours was found to be the optimum time (inoculum age). Using this condition, an improvement in the glycerol consumption and butanol and 1,3-PDO production was achieved, resulting in $45.62 \pm 3.81,12.40 \pm 0.26 \mathrm{gl}^{-1}$, and $7.45 \pm 0.86 \mathrm{gl}^{-1}$, respectively.

\section{Effect of $\mathrm{N}_{2}$ sparging and $\mathrm{pH}$}

The fermentation of glycerol by the strain $\mathrm{M} 2$ at $\mathrm{pH} 6.0$ and different $\mathrm{N}_{2}$ sparging conditions is shown in Fig. 4. Figure $4 \mathrm{a}$ and $\mathrm{b}$ illustrates the solvent and acid production, respectively, in the experiment conducted at $\mathrm{pH} 6.0$ using $0.5 \mathrm{vvm} \mathrm{N}_{2}$ during the whole fermentation. Figure $4 \mathrm{c}$ and $\mathrm{d}$ corresponds to the experiment conducted at $\mathrm{pH} 6.0$ in which $0.1 \mathrm{vvm} \mathrm{N}_{2}$ was supplied only during the lag phase.

The maximum glycerol consumption $\left(74.93 \mathrm{~g}^{-1}\right)$ was obtained in the fermentation controlled at $\mathrm{pH} 6.0$, in which $0.5 \mathrm{vvm} \mathrm{N}_{2}$ was supplied to the culture medium during the whole fermentation. However, the butanol titer was only $8.93 \mathrm{gl}^{-1}$ and a high amount of 1,3-PDO (19.13 $\mathrm{gl}^{-1}$ ) was produced. In the second experiment controlled at $\mathrm{pH} 6.0$, in which $0.1 \mathrm{vvm} \mathrm{N}_{2}$ was supplied to the culture only until cells started to grow, glycerol consumption decreased to $61 \mathrm{gl}^{-1}$. In this case, the final butanol and 1,3-PDO titers were $9.28 \mathrm{gl}^{-1}$ and $15.76 \mathrm{gl}^{-1}$, respectively. Therefore, this condition led to an increase in the butanol yield and resulted in the highest butanol volumetric productivity (Table 2 ).

The fermentation controlled at $\mathrm{pH} 5$ resulted in a glycerol consumption of only $43.51 \mathrm{gl}^{-1}$ (Fig. $4 \mathrm{e}$ and $\mathrm{f}$ ). However, the butanol titer was $9.5 \mathrm{gl}^{-1}$, which resulted in higher butanol yield in

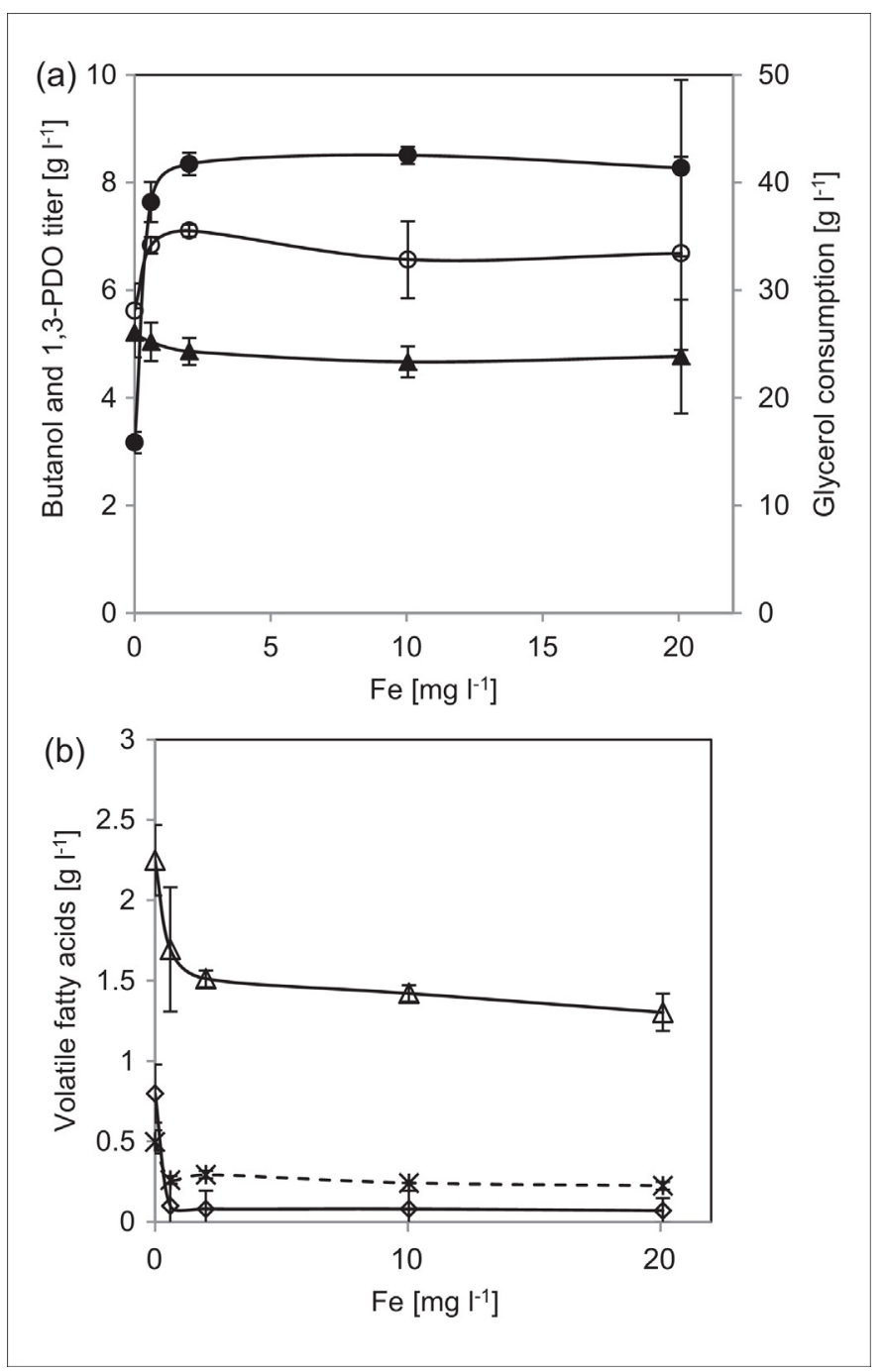

Figure 2. Influence of iron concentration on: (a) butanol titer $(\bullet), 1,3$-propanediol $(\mathrm{PDO})$ titer $(\boldsymbol{\Delta})$ and glycerol consumption $(\bigcirc)$; (b) lactic acid $(\Delta)$, acetic acid $(\mathcal{*})$ and butyric acid $(\diamond)$ concentrations. 


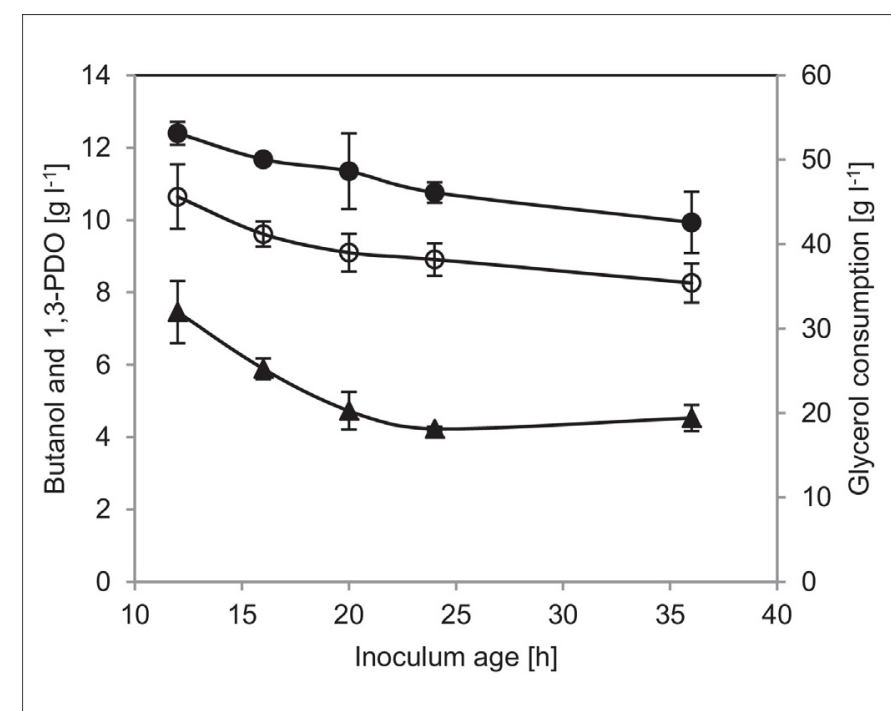

Figure 3. Influence of inoculum age on butanol titer (•), 1,3-propanediol (PDO) titer $(\boldsymbol{\Delta})$ and glycerol consumption $(\bigcirc)$

comparison with the fermentations conducted at $\mathrm{pH} 6.0$ (Table 2). The concentration of 1,3-PDO reached $8.53 \mathrm{~g} \mathrm{l}^{-1}$. The fermentation was much longer, resulting in a marked decrease in the butanol volumetric productivity (Table 2 ).

\section{Discussion}

C. pasteurianum DSM 525 was not able to grow in solid culture medium containing $12 \mathrm{gl}^{-1}$ of butanol. However, in this work a mutant strain (M2) able to grow at this butanol concentration was isolated, also showing an increase in the production of butanol in comparison with the parent strain.

The lower concentration of acids at the end of the glycerol fermentation by the strain M2 indicates that either a higher amount of these acids was re-assimilated during the fermentation, thus leading to the higher butanol titer observed; or a lower production of acids and a higher production of butanol directly via pyruvate-butyryl CoA-butyraldehyde-butanol (Fig. 1) occurred. This result is in agreement with the ones reported by Formanek et al. [34] using the mutant strain C. beijerinckii BA101. The authors found that even though the initial levels of acetic and butyric acids produced by the strain BA101 were comparable to those observed for the parent strain ( $C$. beijerinckii NCIMB 8052), a higher amount was recycled, thereby contributing with additional carbon to the production of neutral solvents.

Venkataramanan et al. [35] studied the toxic effect of butanol on the $C$. pasteurianum metabolism and showed that when butanol was added to a 48 hours culture at concentrations above $5 \mathrm{~g} \mathrm{l}^{-1}$, the endogenous production of this compound was completely inhibited. In the current work, the isolated strain M2 was able to produce butanol when this compound was added at the beginning of the fermentation even at a concentration of $10 \mathrm{gl}^{-1}$, which demonstrates its higher butanol tolerance as compared to the wild type parent strain.

The different butanol titers obtained in the cultures of M2 challenged with $10 \mathrm{gl}^{-1}$ of butanol and the control (no butanol externally added) suggest that other variables should influence the C. pasteurianum metabolism. In fact, Malaviya et al. [2] showed that factors as the inoculum age, initial $\mathrm{pH}$ and $\mathrm{pH}$ control directly influence the production of butanol from glycerol by $C$. pasteurianum.
Based on the previous results, the effect of iron concentration and inoculum age on the production of butanol by the strain M2 was studied. Besides its negative effect on the glycerol consumption and butanol production, the iron limitation resulted in a higher concentration of acids at the end of the fermentation and consequently, in a lower final $\mathrm{pH}(4.68 \pm 0.01$ versus $5.05 \pm 0.02$ in the cultures in which Fe was supplemented) (Fig. 2). These results suggest a lower re-assimilation of acids (acetic and butyric), probably as a consequence of a reduced activity of iron-containing alcohol dehydrogenases present in this microorganism [28]. Moreover, a high lactate concentration was observed, thus indicating that the conversion of pyruvate to acetyl-CoA (Fig. 1) was partially blocked, which could have contributed to the lower $\mathrm{pH}$ value observed at the end of the fermentation by limiting the production of hydrogen. The results herein obtained are in good agreement with the ones reported by Dabrock et al. [6] who also evaluated the effect of iron limitation in the fermentation of glycerol by C. pasteurianum DSM 525; however are opposite to the ones obtained by other Clostridium spp. using glucose as substrate [36,37].

Overall, an increase in the inoculum age negatively affected the C. pasteurianum metabolism (Fig. 3). Malaviya et al. [2] found that 18 hours was the optimum inoculum age for the production of butanol from glycerol by C. pasteurianum DSM 525. Nevertheless, the authors reported similar butanol production values for 18 hours and 12 hours $\left(6.6 \pm 0.16 \mathrm{gl}^{-1}\right.$ vs $\left.5.8 \pm 0.08 \mathrm{gl}^{-1}\right)$, that is, the inoculum age that was found to be the optimal in the current work. Likewise, herein it was shown that the production of butanol decreased with the inoculum age. Mallette et al. [30] also studied the effect of the inoculum age on $C$. pasteurianum growth using glucose as the carbon source. They found that both cell generation time and lag period increased with the inoculum age, for which the optimum was found to be 12 hours.

Interestingly, 12 hours is within the range in which Gutierrez and Maddox [38,39] reported that $C$. acetobutylicum cells remain motile. The authors reported a significant improvement in the solvent production when $C$. acetobutylicum cells were transferred at the time corresponding to a maximum cell motility; thus suggesting that strongly motile cells are more solventogenic than weakly ones as they are attracted to fermentable sugars and undissociated acids, while being repelled by solvents. However, the relation between cell motility, solvent capacity and chemotaxis should be further studied.

Since iron limitation adversely affected the metabolism of the strain and the optimum Fe concentration found in the experiments conducted in serum bottles cannot be generalized to the bioreactor experiments, a higher $\mathrm{FeSO}_{4} \cdot 7 \mathrm{H}_{2} \mathrm{O}$ concentration was used to ensure an excess of this nutrient. Under this condition, and independently of the other variables tested, the high optical density obtained is noteworthy. It has been reported that the maximum $\mathrm{OD}_{600}$ achieved by butyric acid clostridia corresponds to 10-11 [40], which is in agreement with Malaviya et al. [2]. In the current work, a maximum $\mathrm{OD}_{600}$ of 15.9 , corresponding to $5.13 \mathrm{~g}$ of cells $\mathrm{l}^{-1}$ was obtained in the fermentation conducted at $\mathrm{pH} 6.0$ in which $0.5 \mathrm{vvm} \mathrm{N}_{2}$ was used during the whole fermentation (Fig. 4a). When $\mathrm{N}_{2}$ was used only during the lag phase this value slightly decreased to 12.9 (Fig. 4c). However, the same yield of DCW produced per glycerol consumed $\left(0.07 \mathrm{~g} \mathrm{~g}^{-1}\right)$ was obtained in both experiments.

Although fermentations conducted at $\mathrm{pH} 6.0$ resulted in higher glycerol consumption and 1,3-PDO titer as compared to the serum bottles experiments, the butanol titer and yield were significantly lower, which can be related with the specific production of hydrogen. In Clostridium spp. pyruvate is oxidized by pyruvate: ferredoxin oxidoreductase (PFOR) to acetyl-CoA and $\mathrm{CO}_{2}$, with electrons being transferred to ferredoxin (Fd). Hydrogen is 
(a)

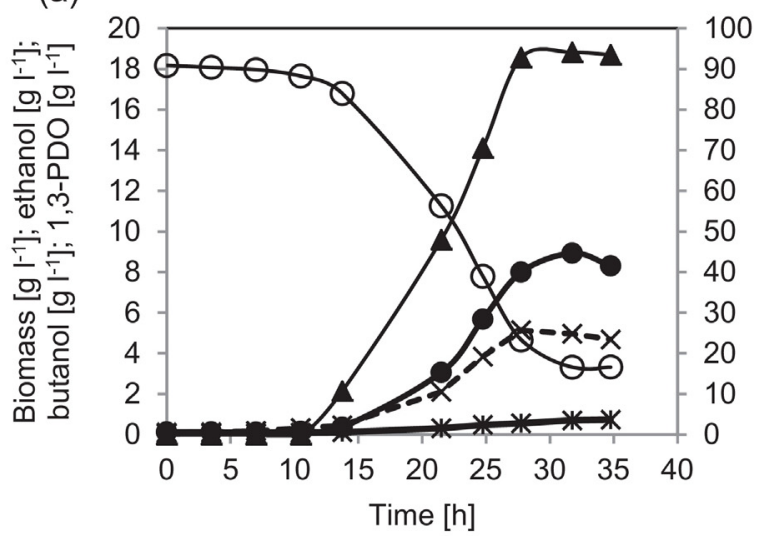

(c)

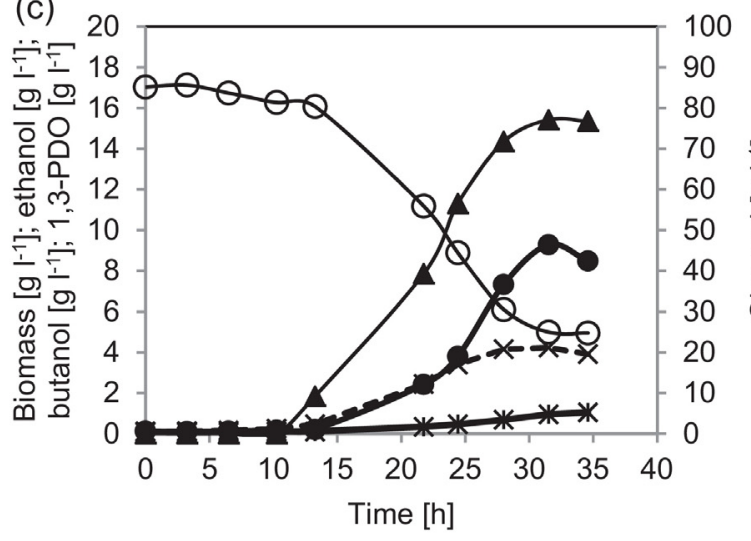

(e)

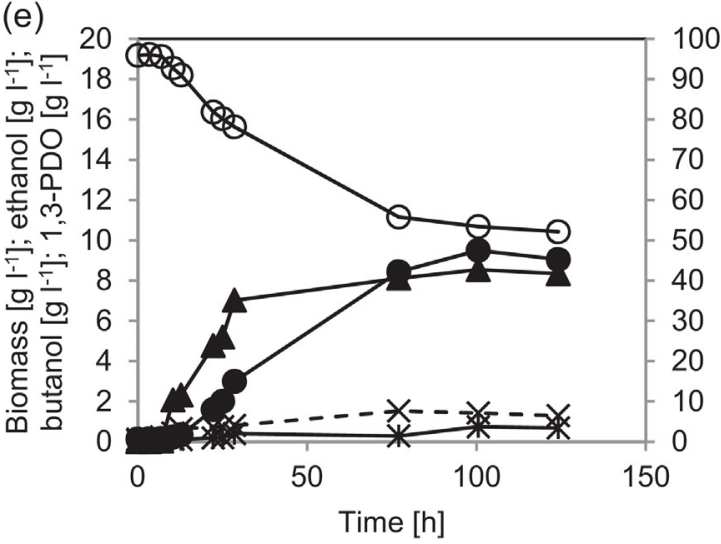

(b)

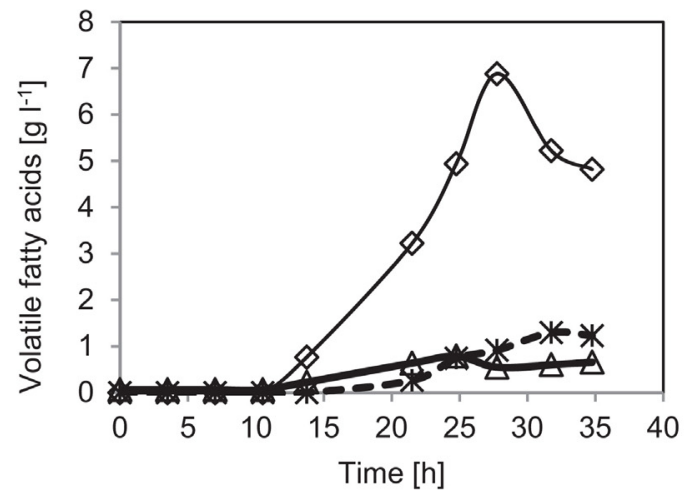

(d)

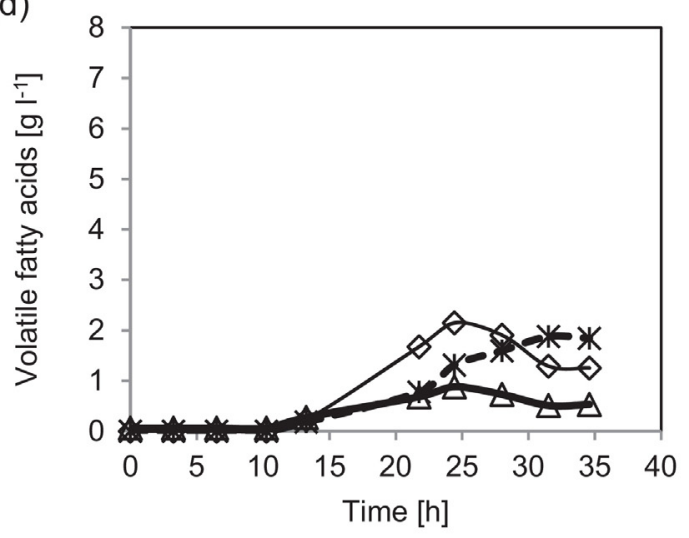

(f)

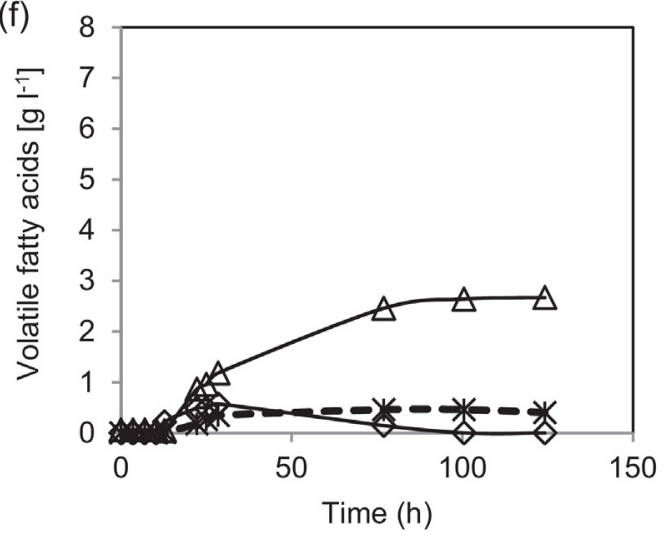

Figure 4. Fermentation of glycerol by the mutant strain (M2) of Clostridium pasteurianum DSM 525 with $\mathrm{pH}$ control and different $\mathrm{N}_{2}$ sparging conditions. (a,b) pH=6.0; $\mathrm{N}_{2}=0.5 \mathrm{vvm} ;(\mathbf{c}, \mathbf{d}) \mathrm{pH}=6.0 ; \mathrm{N}_{2}=0.1 \mathrm{vvm}$ during the lag phase; (e,f) pH = 5 and $\mathrm{N}_{2}$ sparging of $0.1 \mathrm{vvm}$ during the lag phase. Butanol $(\bullet)$, ethanol ( $*$ ), $1,3-$ propanediol (PDO) $(\boldsymbol{\Delta})$, glycerol $(\bigcirc)$ biomass $\left(\mathrm{OD}_{600 \mathrm{~nm}}\right)(\times)$, butyrate $(\diamond)$, acetate $(*)$ and lactate $(\Delta)$.

produced by the hydrogenase enzyme, which catalyses proton reduction using electrons from Fd (Fig. 1). Under certain conditions, the fermentation broth can become supersaturated with hydrogen, limiting the formation of this compound and forcing the organism to channel electrons through NADH: ferredoxin oxidoreductase to reduce other intermediates such as acetyl-CoA to ethanol, as it has been reported for $C$. thermocellum [31]. In C. pasteurianum, an inhibition of hydrogen formation should necessarily result in higher yields of other reduced compounds such as ethanol, butanol, lactate and/or 1,3-PDO to maintain the redox balance.

Basically, there are three operational parameters that can influence the concentration of dissolved $\mathrm{H}_{2}$ (and $\mathrm{CO}_{2}$ ) in the fermentation broth, namely pressure, agitation and gas sparging.

The effect of $\mathrm{H}_{2}$ partial pressure on the ABE fermentation ( $C$. acetobutylicum) has been studied by several authors, some of 
Table 2

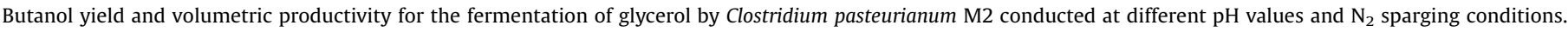

\begin{tabular}{|c|c|c|c|}
\hline \multirow[t]{2}{*}{ Parameter } & \multicolumn{3}{|l|}{ Fermentation } \\
\hline & $\begin{array}{l}\mathrm{pH}=6.0 \\
\left(0.5 \mathrm{vvm} \mathrm{N_{2 }}\right)\end{array}$ & $\begin{array}{l}\mathrm{pH}=6.0\left(0.1 \mathrm{vvm} \mathrm{N}_{2}\right. \\
\text { during the lag phase) }\end{array}$ & $\begin{array}{l}\mathrm{pH}=5.0\left(0.1 \mathrm{vvm} \mathrm{N}_{2}\right. \\
\text { during the lag phase) }\end{array}$ \\
\hline Biomass yield [ $\mathrm{g} \mathrm{g}^{-1}$ ] & 0.07 & 0.07 & 0.03 \\
\hline Butanol yield [ $\left.\mathrm{gg}^{-1}\right]$ & 0.12 & 0.15 & 0.22 \\
\hline Butanol volumetric productivity $\left[\mathrm{gl}^{-1} \mathrm{~h}^{-1}\right]$ & 0.28 & 0.29 & 0.09 \\
\hline 1,3-PDO yield [ $\mathrm{gg}^{-1}$ ] & 0.27 & 0.26 & 0.20 \\
\hline 1,3-PDO volumetric productivity $\left[\mathrm{gl}^{-1} \mathrm{~h}^{-1}\right]$ & 0.67 & 0.49 & 0.08 \\
\hline
\end{tabular}

which have been reviewed by Jones and Wood [41]. Generally, increasing the partial pressure of hydrogen in the headspace during the fermentation has shown to modulate the $A B E$ fermentation resulting in a lower hydrogen production and a higher butanol yield [32]. On the other hand, agitation is an operating parameter that decreases the levels of dissolved $\mathrm{H}_{2}$ and thus affects the solvent ratio by comparison with static cultures [31].

Based on the antecedents above presented, it is reasonable to assume that the higher butanol yield obtained in the serum bottles experiments as compared to the ones conducted in the bioreactor was a consequence of the higher dissolved $\mathrm{H}_{2}$ concentration. Similar arguments can explain the differences observed in the butanol yield between cultures conducted at $\mathrm{pH} 6.0$ with and without $\mathrm{N}_{2}$ sparging. Nitrogen sparging has been shown to restore $\mathrm{H}_{2}$ production when hydrogenase is inhibited by a high $\mathrm{H}_{2}$ partial pressure [42]. In this context, the results gathered in the current work suggest that although the experiments were conducted under agitation, this condition was not enough to avoid hydrogenase partial inhibition by dissolved $\mathrm{H}_{2}$. Thus, $\mathrm{N}_{2}$ sparging alleviated hydrogenase inhibition, favouring the production of biomass and 1,3-PDO, similar to the findings reported by Chatzifragkou et al. [43] working with Clostridium butyricum VPI 1718.

The general consensus is that fermentations conducted at relatively high $\mathrm{pH}$ values produce acids rather than solvents, whereas the reverse occurs in fermentations performed at relatively low $\mathrm{pH}$ values [44]. However, there is a strong interaction between the medium composition and $\mathrm{pH}$, which differs depending on the strain used. Higher initial substrate concentrations encourage solvent production, even at neutral pH values [45]. Although the production of solvents is favoured at low $\mathrm{pH}$ values, it has been reported that cell growth and substrate utilization are negatively affected under this condition [46,47]. The results gathered in the current work are in good agreement with previous reports. The solvent production observed at $\mathrm{pH} 6.0$ can be explained by the high initial glycerol concentration used. However, since Biebl [5] also reported a good solvent production for $C$. pasteurianum using $50 \mathrm{gl}^{-1}$ glycerol at $\mathrm{pH} 6.0$, it is possible that independently of its concentration in the culture medium, the highly reduced nature of glycerol encourages the production of butanol at relatively high $\mathrm{pH}$ values, which does not occur with other substrates as glucose or lactose.

At $\mathrm{pH} 5.0$ a completely different behaviour was observed, namely the glycerol consumption was notoriously lower as compared to fermentations controlled at $\mathrm{pH} 6.0$ and similar to the serum bottles experiments. The biomass yield decreased to $0.03 \mathrm{~g}$ cells $\mathrm{l}^{-1}$ and even though the higher butanol yield was obtained under this condition, the fermentation was much longer, resulting in a marked decrease in the butanol volumetric productivity (Table 2 ). Besides, unlike the cultures grown at $\mathrm{pH}$ 6.0 , the re-assimilation of butyric acid was complete although the maximum measured concentration was lower (Fig. 4f). This situation, added to the higher butanol yield observed, suggests that at low $\mathrm{pH}$ the genes responsible for acid production are downregulated, which results in lower ATP production; while the genes involved in the butanol production from butyryl-CoA are upregulated. A low ATP production can explain the lower biomass yield, as well as the longer fermentation time observed in the experiment conducted at $\mathrm{pH}$ 5.0.

It is worth mentioning that, independently of the $\mathrm{pH}$ value, the contribution of butyric acid to the production of solvents was minimum and most butanol should have been produced directly from acetyl-CoA through butyryl-CoA (Fig. 1). Even though the production of butyric acid at $\mathrm{pH} 6.0$ was considerable; at this $\mathrm{pH}$ most of the acid is dissociated and therefore it cannot permeate the cell membrane. This is reflected by the low decrease in the measured concentration of butyric acid towards the end of the fermentation (Fig. 4b and d).

Another factor that probably contributed to the higher butanol yield observed in the fermentation run at $\mathrm{pH} 5.0$ is a low hydrogenase activity. It has been reported that hydrogenase activity measured in whole cells from acid-producing cultures at pH 5.8 is about 2.2 times higher than that measured in solventproducing cultures at $\mathrm{pH} 4.5$ [48].

An interesting fact that can be observed in Fig. $4 \mathrm{a}$ and $\mathrm{c}$ is that most butanol was produced when cells were in the exponential phase, as also showed by Biebl [5]. This behaviour completely differs from the traditional ABE fermentation (C. acetobutylicum) [49] and also from the glucose fermentation by $C$. pasteurianum [50] in which, even though solvent production can be observed in the late exponential growth phase, most solvent accumulation occurs beyond it. A possible explanation is that the high degree of reduction of glycerol stimulates an early initiation of solvent production. Furthermore, in the case of the glucose fermentation, a clear re-assimilation of acids occurs in C. acetobutylicum [49], which does not occur in C. pasteurianum [50]. Moreover, it is known that the initiation of solvent production and sporulation are both regulated by the protein SpoOA [51-53]. Therefore, the fact that butanol is produced from the beginning of the fermentation and that a great part of it is formed during the exponential growth phase suggests that sporulation and solvent production in $C$. pasteurianum could be uncoupled and therefore, independently regulated.

\section{Conclusions}

In this work we showed that random mutagenesis in solid culture medium is an efficient tool as alternative to the classical random mutagenesis in liquid medium. The experiments conducted led to an improvement of the strain regarding its butanol tolerance. The butanol titer obtained is higher than the values reported in the literature on the production of butanol by $C$. pasteurianum in serum bottles, and are also in agreement with the butanol tolerance of the mutant strain. 
The concentration of iron and the inoculum age were confirmed as key variables in the fermentation of glycerol by $C$. pasteurianum. Overall, a young inoculum is required to assure good glycerol consumption. Iron sufficient concentrations, low $\mathrm{pH}$ and high operational pressure are the conditions required to favour the production of butanol. On the other hand, iron limitation, relatively high $\mathrm{pH}$ and a standard pressure favours the production of 1,3-PDO. Moreover, $\mathrm{N}_{2}$ sparging showed to be a suitable strategy to maximize the final titer, yield and productivity of 1,3-PDO.

C. pasteurianum constitutes a potential platform for the industrial production of butanol and 1,3-PDO, being its high tolerance to glycerol and its unique ability to produce both compounds from this substrate the main advantages over other solventogenic Clostridium species. It is expected that $C$. pasteurianum DSM 525 genome sequence and annotation, along with currently available mutational tools specific for Clostridium spp. and recent promising advances towards an efficient manipulation of this microorganism will promote further exploration of its metabolism to fully exploit its capacities through a systems biology approach and directed mutagenesis.

\section{Acknowledgements}

The authors acknowledge the financial support from the Strategic funding of UID/BIO/04469/2013 unit and project ref. RECI/BBB-EBI/0179/2012 (project number FCOMP-01-0124FEDER-027462) and R. Gallardo's doctoral grant (ref SFRH/BD/ 42900/2008) funded by Fundação para a Ciência e a Tecnologia. The authors thank the MIT-Portugal Program for the support given to R. Gallardo.

\section{References}

[1] Lee SY, Park JH, Jang SH, Nielsen LK, Kim J, Jung KS. Fermentative butanol production by Clostridia. Biotechnol Bioeng 2008;101:209-28.

[2] Malaviya A, Jang YS, Lee SY. Continuous butanol production with reduced byproducts formation from glycerol by a hyper producing mutant of Clostridium pasteurianum. Appl Environ Microbiol 2011;93:1485-94.

[3] Moon C, Lee CH, Sang BI, Um Y. Optimization of medium compositions favoring butanol and 1,3-propanediol production from glycerol by Clostridium pasteurianum. Bioresour Technol 2011;102:10561-8.

[4] Taconi KA, Venkataramanan KP, Johnson DT. Growth and solvent production by Clostridium pasteurianum ATCC $\mathbb{R} 6013^{\mathrm{TM}}$ utilizing biodiesel-derived crude glycerol as the sole carbon source. Environ Prog Sustain Energy 2009;28: $100-10$.

[5] Biebl H. Fermentation of glycerol by Clostridium pasteurianum - batch and continuous culture studies. J Ind Microbiol Biotechnol 2001;27:18-26.

[6] Dabrock B, Bahl H, Gottschalk G. Parameters affecting solvent production by Clostridium pasteurianum. Appl Environ Microbiol 1992;58:1233-9.

[7] Sabra W, Groeger C, Sharma PN, Zeng AP. Improved n-butanol production by a non-acetone producing Clostridium pasteurianum DSMZ 525 in mixed substrate fermentation. Appl Microbiol Biotechnol 2014;98:4267-76.

[8] Hermann M, Fayolle F, Marchal R, Podvin L, Sebald M, Vandecasteele JP. Isolation and characterization of butanol-resistant mutants of Clostridium acetobutylicum. Appl Environ Microbiol 1985;50:1238-43.

[9] Hermann M, Fayolle F, Marchal R. Production of Clostridium acetobutylicum mutants of high butanol and acetone productivity, the resultant mutants and the use of these mutants in the joint production of butanol and acetone. US Patent. US 4757010 A. 88.07.12.

[10] Lemmel SA. Mutagenesis in Clostridium acetobutylicum. Biotechnol Lett 1985;7:711-6.

[11] Alsaker KV, Paredes C, Papoutsakis ET. Metabolite stress and tolerance in the production of biofuels and chemicals: gene-expression-based systems analysis of butanol, butyrate, and acetate stresses in the anaerobe Clostridium acetobutylicum. Biotechnol Bioeng 2010;105:1131-47.

[12] Borden JR, Papoutsakis ET. Dynamics of genomic-library enrichment and identification of solvent tolerance genes for Clostridium acetobutylicum. Appl Environ Microbiol 2007;73:3061-8.

[13] Tomas CA, Beamish J, Papoutsakis ET. Transcriptional analysis of butanol stress and tolerance in Clostridium acetobutylicum. J Bacteriol 2004;186: 2006-18.

[14] Venkataramanan KP, Jones SW, McCormick KP, Kunjeti SG, Ralston MT, Meyers BC, et al. The Clostridium small RNome that responds to stress: the paradigm and importance of toxic metabolite stress in C. acetobutylicum. BMC Genomics 2013;14:849.
[15] Wang Q Venkataramanan KP, Huang H, Papoutsakis ET, Wu CH. Transcription factors and genetic circuits orchestrating the complex, multilayered response of Clostridium acetobutylicum to butanol and butyrate stress. BMC Syst Biol 2013;7:120.

[16] Al-Hinai MA, Fast AG, Papoutsakis ET. Novel system for efficient isolation of Clostridium double-crossover allelic exchange mutants enabling markerless chromosomal gene deletions and DNA integration. Appl Environ Microbiol 2012;78:8112-21.

[17] Heap JT, Kuehne A, Ehsaan M, Cartman ST, Cooksley CM, Scott JC, et al. The clostron: mutagenesis in clostridium refined and streamlined. J Microbiol Methods 2010;80:49-55.

[18] Pyne ME, Moo-Young M, Chung DA, Chou CP. Development of an electrotransformation protocol for genetic manipulation of Clostridium pasteurianum. Biotechnol Biofuels 2013;6:50.

[19] Annous BA, Blaschek HP. Isolation and characterization of Clostidium acetobutylicum mutants with enhanced amylolytic activity. Appl Environ Microbiol 1991;57:2544-8.

[20] Jain MK, Beacom D, Datta R. Mutant strain of Clostridium acetobutylicum and process for making butanol. US Patent. US 5192673 A. 93.03.09.

[21] Shibuya T, Morimoto K. A review of the genotoxicity of 1-ethyl-1-nitrosourea. Mutant Res 1993;297:3-38.

[22] Budavari S, editor. The Merck Index. 11th ed. Rahway, USA: Merck and Co Inc.; 1989.

[23] Flibotte S, Edgley ML, Chaudhry I, Taylor J, Neil SE, Rogula A, et al. Wholegenome profiling of mutagenesis in Caenorhabditis elegans. Genetics 2010;185:431-41.

[24] Tong HH, Park JH, Brady T, Weghorst CM, D‘Ambrosio SM. Molecular characterization of mutations in the hprt gene of normal human skin keratinocytes treated with N-ethyl-N-nitrosourea: influence of O6alkylguanine alkyltransferase. Environ Mol Mutagen 1997;29:168-79.

[25] Gheshlaghi R, Scharer JM, Moo-Young M, Chou CP. Metabolic pathways of clostridia for producing butanol. Biotechnol Adv 2009;27:764-81.

[26] Graves MC, Rabinowitz JC. Cloning and nucleotide sequence determination of the Clostridium pasteurianum ferredoxin gene. Proc Natl Acad Sci USA 1985;82:1653-7.

[27] Adams MWW, Eccleston E, Howard JB. Iron-sulfur clusters of hydrogenase I and hydrogenase II of Clostridium pasteurianum. Proc Natl Acad Sci USA 1989;86:4932-6.

[28] Rappert S, Song L, Sabra W, Wang W, Zeng AP. Draft genome sequence of type strain Clostridium pasteurianum DSM 525 (ATCC 6013), a promising producer of chemicals and fuels. Genome Announc 2013;1:1-2.

[29] Hornbaek T, Nielsen AK, Dynesen J, Jakobsen M. The effect of inoculum age and solid versus liquid propagation on inoculum quality of an industrial Bacillus licheniformis strain. FEMS Microbiol Lett 2004;236:145-51.

[30] Malette MF, Reece P, Dawes EA. Culture of Clostridium pasteurianum in defined medium and growth as a function of sulfate concentration. Appl Environ Microbiol 1974;28:999-1003.

[31] Doremus MG, Linden JC, Moreira AR. Agitation and pressure effects on acetone-butanol fermentation. Biotechol Bioeng 1985;27:852-60.

[32] Yerushalmi L, Volesky B. Importance of agitation in acetone-butanol fermentation. Biotechnol Bioeng 1985;28:1297-305.

[33] Gallardo R, Alves M, Rodrigues LR. Modulation of crude glycerol fermentation by Clostridium pasteurianum DSM 525 towards the production of butanol. Biomass Bioenerg 2014;71:134-43.

[34] Formanek J, Mackie R, Blaschek HP. Enhanced butanol production by Clostridium beijerinckii BA101 grown in semidefined P2 medium containing 6 percent maltodextrin or glucose. Appl Environ Microbiol 1997:63:2306-10.

[35] Venkataramanan KP, Kurniawan Y, Boatman JJ, Haynes CH, Taconi KA, Martin L, et al. Homeoviscous response of Clostridium pasteurianum to butanol toxicity during glycerol fermentation. J Biotechnol 2014;179:8-14.

[36] Junelles AM, Janiti-Idrissi R, Petitdemange H, Gay R. Iron effect on acetonebutanol fermentation. Curr Microbiol 1988;17:299-303.

[37] Peguin S, Soucaille P. Modulation of carbon and electron flow in Clostridium acetobutylicum by iron limitation and methyl viologen addition. Appl Environ Microbiol 1995;61:403-5.

[38] Gutierrez NA, Maddox IS. Role of chemotaxis in solvent production by Clostridium acetobutylicum. Appl Environ Microbiol 1987:53:1924-7.

[39] Gutierrez NA, Maddox IS. The effect of some culture maintenance and inoculum development techniques on solvent production by Clostridium acetobutylicum. Can J Microbiol 1987;33:82-4.

[40] Papoutsakis ET. Engineering solventogenic clostridia. Curr Opin Biotechnol 2008;19:420-9.

[41] Jones DT, Woods DR. Acetone-butanol fermentation revisited. Microbiol Rev 1986:50:484-524

[42] Su TM, Lamed R, Lobos JH. Effect of stirring and $\mathrm{H}_{2}$ on ethanol production by thermophilic fermentation. Proceedings of the 2nd World Congress of chemical engineering and world chemical exposition. . p. 353-6.

[43] Chatzifragkou A, Aggelis G, Komaitis M, Zeng AP, Papanikolaou S. Impact of anaerobiosis strategy and bioreactor geometry on the biochemical response of Clostridium butyricum VPI 1718 during 1,3-propanediol fermentation. Bioresour Technol 2011:102:10625-32.

[44] Maddox IS. The acetone-butanol-ethanol fermentation: recent progress in technology. Biotechnol Genet Eng Rev 1989;7:189-220.

[45] Holt RA, Stephens GM, Morris JG. Production of solvents by Clostridium acetobutylicum cultures maintained at neutral pH. Appl Environ Microb 1984;48:1166-70 
[46] Ennis BM, Maddox IS. Use of Clostridium acetobutylicum P262 for production of solvents from whey permeate. Biotechnol Lett 1985;7:601-6.

[47] Marchal R, Blanchet D, Vandecasteele JP. Industrial optimization of acetonebutanol fermentation: a study of the utilization of Jerusalem artichokes. Appl Microbiol Biotechnol 1985;23:92-8.

[48] Kim BH, Zeikus JG. Importance of hydrogen metabolism in regulation of solventogenesis by Clostridium acetobutylicum. Dev Ind Microbiol 1985;26: $1-14$.

[49] Harris LM, Desai RP, Welker NE, Papoutsakis ET. Characterization of recombinant strains of the Clostridium acetobutylicum butyrate kinase inactivation mutant: need for new phenomenological models for solventogenesis and butanol inhibition? Biotechnol Bioeng 2000;67:1-11.
[50] Harris J, Mulder R, Kell DB, Walter RP, Morris JG. Solvent production by Clostridium pasteurianum in media of high sugar content. Biotechnol Lett 1986;8:889-92.

[51] Alsaker KV, Spitzer TR, Papoutsakis ET. Transcriptional analysis of spo0A overexpression in Clostridium acetobutylicum and its effect on the cell's response to butanol stress. J Bacteriol 2004;186:1959-71.

[52] Harris L, Welker E, Papoutsakis E. Northern, morphological, and fermentation analysis of $5 p 00 \mathrm{~A}$ inactivation and overexpression in Clostridium acetobutylicum ATCC 824. J Bacteriol 2002;184:3586-97.

[53] Ravagnani A, Jennert KCB, Steiner E, Grü nberg R, Jeffries JR, Wilkinson SR, et al. Spo0A directly controls the switch from acid to solvent production in solventforming clostridia. Mol Microbiol 2000;37:1172-85. 